\title{
Funções da creche segundo suas trabalhadoras: situando o cuidado da criança no contexto educativo*
}

\author{
FUNCTIONS OF THE NURSERY ACCORDING TO ITS WORKERS: PLACING THE CHILD'S EDUCATION \\ INTO THE EDUCATIONAL CONTEXT
FUNCIONES DE LOS JARDINES INFANTILES SEGÚN SUS TRABA JADORAS: SITUANDO EL CUIDADO DE LOS NIÑOS EN EL CONTEXTO EDUCATIVO

\section{Maria De La Ó Ramallo Veríssimo1, Rosa Maria Godoy Serpa da Fonseca²}

\section{RESUMO}

Esta investigação teve como objetivo apreender e analisar as representações de trabalhadoras de creches acerca do cuidado da criança. Os dados foram coletados em três creches de uma universidade pública, em São Paulo - SP, mediante entrevistas individuais e uma oficina pedagógica. Os resultados evidenciaram que as trabalhadoras buscam caracterizar seu trabalho como educativo para conferir-lhe maior profissionalismo, colocando o cuidado como função de suporte. Discute-se a contribuição da Enfermagem na definição de um corpo teórico-conceitual sobre o cuidado da criança em creches visando o necessário alcance da integração das funções de cuidar e educar inerentes a esses serviços.

\section{PALAVRAS-CHAVE}

Creches. Cuidado da criança. Educação infantil.

Saúde infantil.

Cuidados de enfermagem.

\begin{abstract}
This investigation had the aim of gathering and analyzing the representations of workers in nurseries regarding childcare. The data was collected in three nurseries of a São Paulo, SP, Public University, through individual interviews and a pedagogical workshop. The results showed that the workers try to characterize their work as educational to make it more professional, placing the care as a support function. The Nursing contribution is discussed in the definition of a theoreticalconceptual body on the care of children in nurseries aiming for the necessary reach of the integration of the caring-for and educational functions inherent to these services.
\end{abstract}

\section{KEYWORDS}

Child day-care centers. Child care. Child rearing. Child welfare. Nursing care.

\section{RESUMEN}

Esta investigación tuvo como objetivo tomar y analizar las representaciones de las trabajadoras de los jardines de infancia acerca del cuidado de los niños. Los datos fueron colectados em tres jardines de infancia de una universidad pública en San Pablo- SP, a través de entrevistas individuales y un taller pedagógico. Los resultados evidenciaron que las trabajadoras buscan caracterizar su trabajo como educativo para conferirle mayor profesionalismo, colocando el cuidado como función de soporte. Se discute la contribución de la Enfermería en la definición de un cuerpo teórico-conceptual sobre el cuidado de los niños en jardines de infancia visando el alcance necesario de integración de las funciones de cuidar y educar inherentes a esos servicios.

\section{PALABRAS-CLAVE}

Jardines infantiles. Cuidado del niño. Crianza del niño. Bienestar del niño. Atencion de enfermeria.
* Excerto da tese "O olhar de trabalhadoras de creches sobre o cuidado da criança", apresentada à Escola de Enfermagem da USP, em 2001.

1 Enfermeira. Professora Doutora do

Departamento de Enfermagem MaternoInfantil e Psiquiátrica da Escola de Enfermagem da USP.

mdlorver@usp.br.

2 Enfermeira. Professora Titular do Departamento de Enfermagem em Saúde Coletiva da Escola de Enfermagem da Universidade de São Paulo. Orientadora deste estudo. 


\section{INTRODUÇÃO}

Em nosso meio, é corrente a visão de que as creches são serviços para crianças pobres, cuja qualidade de atendimento é precária, podendo constituir-se até mesmo em risco ao desenvolvimento infantil. Tal visão justificase pelo histórico de implantação desses serviços e pelas precárias condições em que grande parte deles encontra-se, a despeito de todos os conhecimentos acumulados sobre as necessidades e direitos infantis ${ }^{(1-3)}$.

A crítica ao modelo assistencialista, que caracterizou o atendimento desde os primórdios da creche, tem sido feita mediante ênfase na sua missão educativa ${ }^{(1-3)}$. Sob a justificativa de que a missão da creche ou préescola é educar, muitas instituições têm chegado ao extremo de organizar sua programação em torno de atividades pedagógicas exclusivamente, dando tarefas para a casa e afirmando que lugar de brincar é em casa, não na escola.

Entendemos que as concepções elaboradas nesse formato excludente incorrem em reducionismo, pois rejeitam funções inerentes à creche e culminam na atenção parcializada, além de restringirem a possibilidade de utilizar as contribuições das diferentes disciplinas para a construção de um projeto de atendimento integrado e global à criança. Visando contribuir para a superação dessas questões, desenvolveu-se esta investigação, cujo objetivo foi apreender e analisar as representações de profissionais de creches acerca do cuidado da criança.

\section{METODOLOGIA}

O cenário do estudo foram três creches de uma Universidade Pública, situadas no município de São Paulo, tendo-se como premissa que as creches universitárias são excelentes experiências que reúnem teoria e prática, permitindo o aprofundamento científico do atendimento.

A população foi constituída por 16 trabalhadoras, em dois grupos. O grupo das educadoras, responsáveis pelas atividades diretas às crianças, formou-se após adesão espontânea de 10 trabalhadoras a convite da pesquisadora, durante reuniões rotineiras nas creches. Uma destas participou apenas do primeiro encontro, motivo pelo qual optamos por não incluir seus dados no estudo, compondo o grupo com cerca de $14 \%$ do total das educadoras. $\mathrm{O}$ único critério para inclusão foi o vínculo há mais de dois anos na instituição. O outro grupo contou com o total das profissionais das equipes técnicas (7), responsáveis pela coordenação e supervisão das atividades.

Realizamos entrevistas semi-estruturadas com as coordenadoras e uma oficina pedagógica com as educadoras. As entrevistas individuais e coletivas foram gravadas, transcritas na íntegra e submetidas à análise de conteúdo, segundo a técnica de análise temática ${ }^{(4)}$. Ao final da análise, foram obtidas quatro categorias: $A$ creche, $O$ trabalho na creche, $O$ cuidado da criança na creche e $A$ creche e a família. Considerando o grande volume de dados, apresentamos neste texto o conteúdo da categoria $A$ creche, visando subsidiar a reflexão sobre as funções da creche, colocada em pauta com as mudanças atuais devidas à inserção das creches na educação básica, enquanto instituições de educação infantil. Os demais temas serão apresentados em outros artigos.

O projeto foi apreciado por Comitê de Ética e as trabalhadoras assinaram termo de consentimento livre e esclarecido, após conhecerem o objetivo e finalidade do trabalho, forma de coleta dos dados e de apresentação do relatório, e a garantia quanto ao anonimato das informações.

\section{RESULTADOS}

A categoria $A$ creche foi composta pelas subcategorias funções da creche, a vida da criança na creche e controvérsias sobre a creche, que serão apresentadas a seguir.

\section{Funções da creche}

Todas as coordenadoras apontaram como funções da creche educar e cuidar, apresentando, porém, diferentes ênfases. A maioria definiu a creche como instituição de educação, conceituando educação como um processo amplo que engloba a transmissão de conhecimentos, cultura, valores e regras sociais. Para elas, tal processo inclui não só atividades pedagógicas como também o cuidado, o qual foi definido enquanto promotor do bem-estar e das interações na creche. 
Para as crianças, é um espaço de educação. Quando eu cuido eu estou educando, quando eu educo, eu cuido.

Creche serve pra atender crianças de 0 a 6 anos, no que diz respeito a educação e cuidados. Cuidados cada vez mais entendido como função da educação.

O educar pra mim é o todo, educar e cuidar é uma coisa só, e o objetivo mesmo nosso é o pedagógico em primeiro lugar.

A concepção de creche como instituição educativa é recente na história do Brasil, pois, em sua origem, no século XIX, tinha como função primordial a guarda e a proteção infantil, particularmente das crianças pobres. A partir dos anos 70, a sociedade civil passou a lutar organizadamente em defesa de novas propostas para a creche e pré-escola que foram legitimadas pela Constituição Federal de 1988. A educação infantil tornou-se um dever do Estado e direito da criança, embora não obrigatória. $\mathrm{O}$ Estatuto da Criança $\mathrm{e}$ do Adolescente (lei $\mathrm{n}^{\circ}$ 8.069/90) e a Lei de Diretrizes e Bases da Educação (lei no 9394/ 96) vieram definir que as instituições para a criança de 0 a 6 anos sejam subordinadas ao órgão responsável pela educação nos municípios brasileiros.

Uma única coordenadora apontou como função da creche proporcionar o saber constituído como saber escolar: da língua (escrita e leitura), da matemática, das artes e ciências. De acordo com esta visão, defende-se que é função da creche preparar a criança para a escolarização, oferecendo conhecimentos formalizados, para favorecer seu ingresso no ensino fundamental.

[a creche] ensina a ler, escrever, conhecer pintores. Tudo isso faz parte da educação pra ela chegar na primeira série com um conhecimento que ela é capaz. [A parte educativa] são as atividades planejadas previamente, pensadas, não são aleatórias, tem um estudo posterior, qual é a faixa etária, o que nós vamos ensinar pra ela.

Essa concepção surgiu na década de 80 , em experiências isoladas em diversos estados brasileiros e na literatura especializada, visando à superação do determinismo assistencialista em vigor nas instituições de atendimento à criança. Chamados genericamente de educacionais, esses novos modelos enfatizavam o planejamento e programação pedagógica das atividades junto às crianças. Entretanto, em muitos casos, houve importação do modelo do ensino fundamental, criando situações nada compatíveis com as características e necessidades da criança pequena ${ }^{(5)}$. Este é, inclusive, um dos aspectos conflitantes do Referencial Curricular Nacional para a Educação Infantil ${ }^{(3)}$, no qual a educação infantil é tratada, muitas vezes, como ensino, utilizando terminologia e conteúdos disciplinares correntes nos níveis posteriores de ensino, e o cuidado aparece como secundário.

As educadoras manifestaram concepção semelhante à das coordenadoras, destacando que a realização da função pedagógica não pode ser cumprida caso não se propicie o bemestar infantil. Assim, estas percebem o cuidado como função subsidiária e de apoio ao papel educativo do serviço.

\section{O princípio da creche é o bem-estar da criança, tudo é centrado na criança. A troca, a alimentação, o sono, como ambi- ente confortável para a criança. Ela es- tando limpa, bem alimentada, descansa- da, você está criando um ambiente facilitador para poder propor um ambiente de desenvolvimento cognitivo. A nossa parte pedagógica, de linguagem, matemá- tica, é facilitada pelo bem-estar dela, en- tão ela está disponível para aprender.}

Outra função destacada pelas coordenadoras foi favorecer a socialização ou promover situações de interação social, o que entendem como possível graças à diversidade de adultos e crianças com as quais se dá a convivência diária, assim como à variedade de atividades oferecidas. Segundo estas, a aprendizagem das interações sociais favorece o desenvolvimento infantil. Cabe destacar que somente uma educadora citou a importância da experiência da criança na creche para sua socialização.

\section{É importante a criança desde muito peque- na ir para uma escola, para uma creche, ir conviver com outras crianças. Ela se soci- aliza muito cedo, isso é o lado positivo.}

$\mathrm{Na}$ instituição tem os amigos, vai tendo uma relação, experimentando outras pessoas, outros adultos, essa rede de conhecimentos, tanto cognitivo como afetivo, é fundamental.

Esse é um aspecto de suma importância, particularmente considerando que nos tempos modernos a família tem sido definida como o lugar da socialização primária ${ }^{()}$. Nos últimos anos,
Funções da creche segundo suas trabalhadoras: situando o cuidado da criança no contexto educativo 
Maria De La Ó R. Veríssimo Rosa Maria G.S. da Fonseca porém, as pesquisas no campo da creche evidenciaram que os limites entre aquilo que tradicionalmente era definido como socialização primária (de incumbência da família) e socialização secundária (de incumbência de outras agências) estão se diluindo cada vez mais ${ }^{(7)}$. Esse dado

coloca em crise as teorias (...) que afirmam a necessidade das crianças em adquirir estruturas estáveis de socialização primária antes de ampliar suas experiências e outras formas de sociabilidade ${ }^{(7)}$.

A questão da socialização precisa, então, receber atenção e reflexão.

Um dos aspectos a estar atento é o fato de que o processo de socialização no ambiente institucional coletivo implica a aprendizagem de normas específicas, muitas vezes diferentes das familiares, que precisam ser analisadas sob várias óticas, inclusive a das influências sobre o desenvolvimento cognitivo e emocional. Crianças que freqüentam creches vivem experiências simultâneas de sociabilidade na família e na creche e,portanto, "não é possível isolar a contribuição da experiência da creche no desenvolvimento da criança”, bem como "a freqüência à creche modifica, direta e indiretamente, a natureza da experiência em família" (7).

Finalmente, os dois grupos de trabalhadoras colocaram que a creche supre necessidades da criança, proporcionando-lhe bem-estar. Para algumas, a creche oferece "o que a família não pode oferecer em virtude de suas condições de vida ": atividades diversificadas, promoção da independência, estimulação do aprendizado da convivência e proteção dos perigos da rua. Foi feita apenas uma referência à creche como um serviço que atende à necessidade da mulher trabalhadora.

Foi possível constatar que toda a atenção do serviço está direcionada para a criança, uma vez que as atividades realizadas visam atender suas necessidades, provendo oportunidades de desenvolver o potencial infantil. É o que buscam alcançar na maneira como organizam o ambiente e a rotina.

Essas falas se coadunam com a idéia que vem sendo difundida atualmente, a respeito da creche como direito da criança e não só da mãe, portanto, potencialmente dirigida a todas as crianças e tendo como finalidade atender suas necessidades específicas de desenvolvimento.
A esse respeito, cremos ser importante aprofundar a reflexão acerca do que postula a literatura: a creche, como serviço, tem como referência a família, pois

é realmente uma abstração pensar nas necessidades da criança como aspectos separados da realidade social na qual se encontra inserida e, portanto, das necessidades da própria família(8).

\section{A vida da criança na creche}

Ao exporem seus conceitos sobre as funções da creche e sobre o cuidado, as coordenadoras descreveram intervenções que julgam fundamentais para o bem-estar da criança. Em todos os depoimentos, pode-se extrair preocupação em proporcionar as condições mais adequadas e satisfatórias para a criança, quais sejam: a vivência de experiências prazerosas, garantia de espaço e tempo para brincar. As intervenções mais destacadas relacionaram-se ao processo de adaptação durante a inserção da criança na creche, à flexibilidade das regras e às formas de garantir a individualidade das crianças.

Alguns itens evidenciados como pontoschave do processo de adaptação apontados pelas coordenadoras podem ser qualificados como ações de cuidado à criança e família, embora não tenham sido assim enunciados, e permitem a individualização do atendimento: 1) fase de conhecimento recíproco creche, família e criança, mediante a realização da entrevista, reunião e exame de saúde; 2) indicação de uma educadora de referência, responsável por acompanhar de perto a criança e a família durante o período de adaptação; 3) entrada gradativa das crianças, permitindo maior atenção nos primeiros momentos de sua presença na creche e 4) presença de um membro da família com a criança até que ela adquira confiança nas educadoras.

Como exemplos de flexibilidade, as coordenadoras relataram mudanças de regras, tais como permitir que as crianças passassem a ter a opção de trazer um brinquedo seu todos os dias, e a organização da rotina que prevê que as crianças possam realizar seu momento de repouso quando o necessitam. Conforme as coordenadoras, as estratégias utilizadas durante a adaptação e a flexibilidade das normas permitem a individualização do atendimento, o que traz um sentimento de segurança, favorável também ao aprendizado ne- 
cessário para lidar com as imposições da convivência em grupo.

Para as educadoras, as intervenções para promover o bem-estar da criança também se iniciam no período de adaptação. Trazer a mãe para participar desse período, deixar a criança com seu objeto de apego, estabelecer uma educadora para referência, promover vínculo afetivo, são exemplos de como atendêla. Da mesma forma, o momento da chegada da criança na creche apareceu como muito significativo, muito importante, pois é esperado que a criança proteste para se despedir dos pais e até mesmo reaja à eminente separação deles. Os cuidados para acolher a criança nesse momento são: recebê-la carinhosamente, oferecer atividades diversifi-cadas para ela escolher, permitir que continue o sono. Além disso, ressaltam a importância do ritual de despedida, pois sabem que a criança precisa ser informada sobre o que vai lhe acontecer e ter segurança de que a mãe ou o pai vai voltar.

No cotidiano, as educadoras realizam uma série de ações que constituem intervenções educativas e de cuidado, e visam favorecer o desenvolvimento infantil. Destacam que tais ações não são iguais para todas as crianças, pois cada uma tem suas demandas, sendo a idade o primeiro fator que as diferencia, havendo uma progressiva autonomia, conforme a idade aumenta. Apontam como objetivos ajudar a criança no aprendizado sobre compartilhar, manter ou melhorar sua auto-estima, e desenvolver autonomia e responsabilidade.

O quanto a gente tem trabalhado esse compartilhar quando eles chegam na creche, no ateliê, na acolhida deles, na hora que eles vão embora.

Me preocupa bastante trabalhar a autoestima da criança. Estar valorizando o desenho que a criança faz, reforçar a auto-estima dela.

Os combinados começam a aparecer de verdade, com significado pra eles, no segundo semestre, no G2, "lembra do nosso combinado?" eles conseguem falar "lembro", eles estão tomando propriedade disso, estão criando autonomia, ficando independentes e tomando um pouco de responsabilidade.

A preocupação de trabalhar com a criança o que significa compartilhar, cooperar, respeitar acordos ou combinados, também é uma forma de promover sua auto-estima e auto-

nomia. Mostra uma concepção de que o crescimento saudável não é aquele em que a pessoa é poupada de todas as dificuldades, mas sim ajudada a aprender a lidar com conflitos, porque eles fazem parte da realidade. Autonomia significa não só o direito de escolha, mas também a conseqüente responsabilidade.

São várias as situações em que as crianças são estimuladas a exercitar a autonomia. São-lhes oferecidas opções concretas, com garantia de que sua escolha será respeitada: o bolo de aniversário, os ateliês e até mesmo a preferência por uma educadora.

\begin{abstract}
Desde o ano passado, a gente viu no berçário que a criança também elege a pessoa, o adulto que irá fazer a adaptação dela. $E$ a gente tem que levar em consideração, respeitar essa opinião, por menor que ela seja, não importa. A gente pode chegar e falar: vamos fazer a adaptação de tal criança. Só que chega no dia, a criança bate o olho e fica com a outra. E aí? Você vai "não, é só com a gente"? Não, a outra educadora assume e faz a adaptação, porque a criança se identificou mais com ela.
\end{abstract}

Destaca-se aqui a capacidade empática das educadoras de identificar a necessidade e o desejo individual das crianças e responder a eles ativamente, o que entendemos como característica de profissionalismo ou de cuidado profissional.

Um aspecto que também as preocupa é o de garantir a atenção individual dentro do coletivo. Isto foi exemplificado com uma situação entre uma criança e a cozinheira, destacando-se que a individualização do atendimento é importante para a criança e também para a educadora, que diz emocionar-se, denotando o grande valor que atribui a essa forma de atenção.

Tem uma criança que gosta muito de salada de fruta, e a [cozinheira] falou: "eu vou fazer salada de fruta especialmente para você" e tinha um outro brincando lá. Ele registrou isso e foi no comecinho do ano. $\mathrm{E}$ ele gosta muito de creme de abacate, e ontem teve creme de abacate, fazia tempo que não tinha. Os pais vêem no cardápio que fica no corredor, aí ele foi lá falou "R., hoje tem creme de abacate?" ela falou "tem". E ele "então quando for na hora da sobremesa depois do almoço, você fala pra todo mundo que é especialmente pra mim", até emociona, por conta do tempo. Já faz quase quatro meses. Tem essa relação também muito próxima que tem um monte de coisa positiva.
Funções da creche segundo suas trabalhadoras: situando o cuidado da criança no contexto educativo 
Maria De La Ó R. Veríssimo Rosa Maria G.S. da Fonseca
A festa de aniversário da criança é outro exemplo da individualização do cuidado:

O dia do aniversário da criança é comemorado na creche. Os maiores escolhem o bolo, o pai e a mãe vêm, vem a avó. Canta parabéns para a criança e o grupo, é um momento muito legal, muito gostoso, e a criança curte mesmo.

Esses exemplos validam que a proposta de atendimento está sendo implementada, que os princípios de respeito às escolhas, de promoção da autonomia e de individualização do cuidado não estão presentes só no discurso, mas também na operacionalização das ações.

Outro aspecto fundamental é a compreensão acerca de como deve ser a relação da educadora com a criança: sem autoritarismo ou imposições.

A justificativa é um fator predominante com relação aos limites às regras, porque tudo a gente sabe justificar e argumentar o porque. Não é "não, e pronto". Existem momentos que a criança pode decidir o que fazer. Há momentos que não, que eu tenho o cuidado de planejar, de estudar, e de trazer isso para o grupo. O momento que eu planejei e que eu pensei em todos, você acaba justificando porque ela tem que fazer aquilo, porque seria legal ela estudar junto.

No relato seguinte, a educadora apresenta como lidou com um problema sobre o qual ela havia comentado no encontro anterior da oficina:

Lembra que eu falei semana passada das caixas? Mudamos a rotina do meu grupo com relação a essas caixas, que eles estavam comendo correndo, para ir brincar. Tive uma conversa de roda, para eles comerem tranqüilos com calma, o que eles gostavam de comer. Acaba de almoçar, vai para a salinha, brincam lá, com as coisas que eles trazem de casa. Eles trazem brinquedos, mas não têm a oportunidade de brincar na salinha deles, só com os amigos. Ou divide com a creche inteira, ou guarda. Encontramos o momento. Dividem com o amigo da salinha, quer ficar no canto sozinho fica. Enquanto isso, a educadora da tarde vai chegando e vai chamando aqueles que estão com sono. Quer dizer, nem eles saíram para disputar a caixa, nem fizeram aquela construção de casa, que eles tinham feito. É lógico, depois que você constrói uma casa com uma caixa, não vai querer sair para dormir. Se a gente tem essa percepção, a gente pode pensar e mudar direções, para o bemestar, para melhorar.
Para atender bem as crianças, as educadoras buscam formas de superar as dificuldades que encontram, como a escassez de brinquedos e os problemas do espaço físico, a fim de tornar a creche um local prazeroso.

A gente vê no nosso relato, o quanto são grandes as dificuldades, e quanto a gente tem superado essas dificuldades e transformado esse ambiente, pra criança gostar da creche.

Finalmente, destacou-se a preocupação com a alimentação:

\begin{abstract}
A alimentação aparece tanto no berçário quanto nos maiores. Quando o bebê não mama, as educadoras ficam desesperadas porque o bebê não comeu. $E$, no módulo 2, que as crianças deixam de comer pra brincar no pátio, as educadoras se preocupam do mesmo jeito porque elas estão deixando de comer também. É uma coisa que permeia todos os grupos, independente da idade.
\end{abstract}

\section{Controvérsias sobre a creche}

O ponto mais discutido pelas educadoras referiu-se à concepção de creche e suas funções. Num primeiro momento, colocaram que, no imaginário da população, há uma confusão sobre essas funções, e explicaram que tal confusão deve-se à própria história desse serviço que teve sempre como premissa o assistencialismo.

A palavra creche é um pouco pejorativo, é difícil de derrubar isso. A creche foi criada porque as mães precisavam trabalhar na época, 100 anos atrás, e tinha que ter um local pra deixar seu filho só pra ser assistido fisicamente.

Assim, as educadoras manifestaram que, segundo o senso comum, a creche é vista como instituição que visa apenas suprir as necessidades de sobrevivência infantil, ou seja, como uma solução para atender crianças cujos pais não podem cumprir seu papel enquanto "os adultos que deveriam ficar com ela [a criança]". As discrepâncias entre essa visão e as propostas atualmente preconizadas, da creche como local de educação e direito da criança, foram representadas por elas como um emaranhado de fios. Ao mesmo tempo, porém, que apontaram tal visão como um problema que enfrentam no contato com os pais e com o público externo à instituição em geral, parece que as educadoras misturam-se a esse imaginário do senso comum e também se sentem confusas, de certa forma. Nesse senti- 
do, enquanto definem educar como função precípua da creche, também afirmam que é seu papel cuidar, pois "as crianças precisam estar bem para sentirem-se dispostas a aprender". Por outro lado, evidencia-se que o cuidado foi incorporado por elas como sinônimo de assistencialismo, o que o distancia de um atributo profissional. Essa idéia denota carência de discussão sobre o modelo de cuidado presente em cada momento da história da creche.

De fato, a conotação pejorativa resulta de uma realidade concreta em que a forma mais difundida sobre essa proposta de atendimento infantil baseia-se numa postura assistencialista, caritativa, visando à população mais desfavo-recida socialmente, centrada na guarda ou abrigo da criança e nas atividades de saúde, higiene e alimentação ${ }^{(1,2)}$. Os enfoques compensatório e médico-higienista, esteios desse atendimento, levaram a uma série de distorções, culminando em propostas cuja tônica, dentre outros sérios problemas, é a falta de capacitação das pessoas que cuidam das crianças. Ainda persiste a concepção estigmatizadora de que a creche, ao invés de uma solução de boa qualidade para atender a criança pequena, seja um "mal necessário"(2). Na verdade, grande parte das instituições ainda tem esse caráter: em 2000, um jornal de grande circulação no estado de São Paulo apresentou como uma das manchetes "Pesquisa mostra má qualidade de creches"(9), trazendo dados de uma investigação nacional realizada pelo Ministério da Previdência e Assistência Social em parceria com o Instituto de Estudos Especiais da Pontifícia Universidade Católica de São Paulo, em 1999. Foram destacados os seguintes problemas: educadores recebendo baixos salários e com escolaridade insuficiente (no Município de São Paulo, apenas $14,7 \%$ dos profissionais das creches públicas concluíram o ensino médio); instalações precárias que não garantem às crianças condições mínimas de uso e baixo investimento em material pedagógico.

\section{Podemos afirmar que \\ o assistencialismo que predominou por longo tempo nas creches nem sempre deu a devida importância à questão da qualidade dos serviços prestados,}

que são

considerados favores oferecidos à população, e os pais não têm direito a qualquer controle ou intervenção sobre o que acontece com seus filhos na creche ${ }^{(10)}$.
Cabe destacar que as creches pesquisadas divergem dessa situação alarmante, pois vêm construindo seu trabalho numa perspectiva e condições totalmente diversas. Por essa razão, as educadoras manifestam confiança de que realizam um trabalho diferenciado e favorável ao desenvolvimento infantil e, por isso, gostariam que possibilidades semelhantes fossem acessíveis a todas as crianças.

As educadoras apontam, ainda, como barreira à compreensão da população em geral sobre a função educativa da creche o fato de que "crianças pequenas não recebem aulas".

Embora as coordenadoras tenham citado muitos pontos positivos, destacaram questões que entendem como desvantagens da creche para a criança: os limites à individualidade gerados pela divisão de tudo e porque todas as decisões se restringem pelos interesses coletivos; a permanência em período integral, considerada muito longa, especialmente para as crianças menores; a ausência de uma figura única de ligação afetiva.

A marca do ambiente institucional é a ausência da família, mas também a divisão de tudo, um espaço onde tudo é coletivo, até o adulto que cuida dele. Na casa se dividem as coisas, mas tem um espaço bastante individualizado, tem uma falta de rotina regradinha, e uma instituição que tem 250 crianças, não dá para cada um comer na hora que quer. Mesmo que eu ache que eu não tenho que respeitar totalmente isso, mas não dá para cada um ter vontades, não posso fazer a cozinha funcionar desse jeito, eu tenho um tanto de flexibilidade que, para algumas crianças, é uma imposição drástica.

Eu questiono um pouco, para a criança muito pequenininha, o período integral. Eu sinto que, às vezes, as crianças pequenas ficam um pouco cansadas. Sabe, aquele momento de ficar no seu cantinho, com as suas coisinhas, e aqui é tudo muito coletivo, na hora de comer todo mundo senta junto, o brinquedo é de todo mundo, por mais que a gente tente deixar um momento de ficar na almofada quietinha, é o barulho, a outra criança. Tem a rotina que tem que se seguir: agora é hora de dormir, agora é hora de comer, que é importante para a criança, para ela se organizar, mas ela precisa um pouco dessa coisa individual, de um cuidado individual, de estar sozinha, sem precisar dividir sempre tudo, os brinquedos, o adulto. Talvez o meio-período seria o ideal.
Funções da creche segundo suas trabalhadoras: situando o cuidado da criança no contexto educativo 
Maria De La Ó R. Veríssimo Rosa Maria G.S. da Fonseca
Essas questões evocam a idéia de que a melhor estrutura para a criança seria o modelo de família nuclear, em seu próprio lar, e que o cuidado que a criança necessita seja intrínseco a essa estrutura. Esta é uma representação social construída bem recentemente na história ocidental. Estudos históricos acerca da família evidenciam seu caráter de instituição social dinâmica, que assume características e sentidos em conformidade com os sistemas de valores, crenças e práticas vigentes no meio e no tempo em que se constitui.

As transformações ocorridas na família desde o período medieval até o contemporâneo, mostram profundas diferenças em sua estrutura e funções ${ }^{(11)}$. Até o século XV, a família era uma realidade moral e social mais do que sentimental. As crianças eram educadas e socializadas na casa de outras famílias que não as suas. Os moralistas e os educadores do século XVII despertaram um sentimento da infância que inspirou toda a educação até o século XX: as crianças como frágeis criaturas de Deus que era preciso preservar e disciplinar. A literatura e a propaganda da nova ordem moral ensinaram aos pais que eles eram guardiões espirituais, responsáveis perante Deus pela alma e pelo corpo de seus filhos. A família deixou de ser apenas uma instituição de direito privado para a transmissão dos bens e do nome, e assumiu uma função moral e espiritual, passando a formar os corpos e as almas. O cuidado dispensado às crianças passou a inspirar sentimentos novos, uma afetividade nova: o sentimento moderno de família ${ }^{(11)}$.

Lembrando que essa formação familiar refere-se particularmente à Europa ocidental, de onde vieram nossos colonizadores, cabe destacar que o discurso da família nuclear como o melhor ambiente de cuidados infantis pressupõe uma família idealizada, em sua estrutura e funções, o que nem sempre corresponde à realidade. Assim, é imperioso aprofundarmos a reflexão acerca de quais são efetivamente as necessidades infantis para o desenvolvimento e como elas podem ser supridas nos diferentes contextos: o familiar, o educativo, o comunitário.

Em relação à questão da divisão do adulto, "se a instituição quiser pautar seu atendimento no modelo materno-substitutivo, precisa garantir o que pede a literatura norteamericana", ou seja, "um adulto para cada 3 crianças de 0 a um ano e meio"(12). Por outro lado, uma concepção de creche como um contexto que, em função de suas características, oferece oportunidades específicas e complementares àquelas da família e constitui um ambiente de socialização e educação de crianças em grupo, complementar à família, e não uma tentativa de reprodução do ambiente familiar,

pode prever uma razão adulto-criança um pouco mais alta. Isso desde que se

organizem espaços mais práticos para os adultos, ao mesmo tempo seguros e estimulantes para os bebês", bem como "estratégias que permitam às crianças relacionarem-se entre si e possibilitem ao adulto maior atenção individual às crianças ou grupos que necessitem ${ }^{(12)}$.

\section{REFLETINDO SOBRE O CUIDADO DA CRIANÇA NO CONTEXTO EDUCATIVO}

A legislação brasileira atual determina que a creche é parte integrante do sistema escolar, mas a política educacional a define como instituição educativa sem caráter escolar, enfatizando que "é no binômio educar e cuidar que devem estar centradas as funções complementares e indissociáveis dessa instituição"(13). Assim,

uma estruturação escolar, por si só, não dá conta da operacio-nalização de modelos de atendimento à criança de 0 a 6 anos, com o caráter multifa-cetado que pressuporia a integração de ações de Saúde, Educação, Assistência Social e Cultura ${ }^{(13)}$.

Como pontos principais dos resultados aqui apresentados, verificamos o predomínio da representação de creche como ambiente educativo, ao lado de uma visão de cuidado como algo necessário e imprescindível, porém cujo valor é inferior em termos de papel profissional. Apesar disto, em consonância com os dados da pesquisa, as creches do estudo caracterizam-se como instituições que privilegiam igualmente o cuidado, embora não o designem explicitamente assim. Em resumo, o que nos permite tal conclusão: identificamos que as regras são orientadas para a criança e, portanto, não interpretadas rigorosamente; a creche é um local onde a criança pode desenvolver laços afetivos com os adultos ou com outras crianças e há uma preocupação com sua tranqüilidade emocional; as educadoras referem-se continuamente às necessidades das crianças, seus desejos e angústias, investindo seus conhecimentos e
Rev Esc Enferm USP 2003; 37(2): 25-34. 
habilidades para detectar e atender as necessidades afetivas, as angústias da separação durante a adaptação e a chegada, tentando lidar com a confusão que muitas vezes se estabelece nesses momentos.

Assim, cabe refletir sobre as razões que levam as trabalhadoras a priorizar a função educativa em seu discurso.

Primeiramente, verificamos a presença da representação de cuidado como fenômeno que não é socialmente reconhecido como trabalho $^{(14)}$. Essa representação decorre de que o cuidado com o corpo da criança implica um trabalho manual, que vem sendo realizado em toda história da humanidade como atividade simplesmente prática, segundo bases empíricas e culturalmente associado a uma tarefa naturalmente feminina e doméstica tendo, portanto, menor valor social. Por outro lado, percebemos que a busca de reconhecimento social quanto ao trabalho realizado, especialmente para as educadoras, encontra resposta na possibilidade de serem consideradas professoras, o que elevaria seu status. Também contribui para essa representação a atual situação político-legal brasileira que definiu a creche e a pré-escola como instituições de Educação Infantil, que compõem a Educação Básica juntamente com o Ensino Fundamental. Por fim, na trajetória para a construção da nova definição para a creche muitas vezes tem-se rejeitado qualquer aspecto assistencial e de cuidado como resquícios da visão caritativa e assistencialista ${ }^{(15)}$ que se quer degredar.

Uma explicação para que o cuidado realizado seja de boa qualidade é a perspectiva educacional defendida nessas creches. Uma vez que há diretrizes claras acerca do objetivo de promover a autonomia e o bem-estar infantil, as ações propostas são delineadas com essa meta. Isso faz com que as atividades contemplem todas as necessidades das crianças, ainda que as trabalhadoras não as estruturem segundo um referencial de processo de cuidados.

Concordamos que a integração cuidareducar é o núcleo do trabalho pedagógico com a criança pequena ${ }^{(8)}$ e permite consolidar a responsabilização pela criança. A creche assume, em parceria com a família, a formação da criança, a transformação do ser natural em um ser social, um cidadão. Assim, uma alternativa para essa questão é pensar a definição da creche como "um contexto de vida num espaço educativo "(8), ou como "um ambiente de cuidado e educação num contexto educativo"(16). Para que essas definições se concretizem, defendemos a contribuição da Enfermagem na construção de um marco referencial que fundamente, dê segurança e valorize para a equipe da creche suas ações de cuidado, fortalecendo a idéia do "cuidado como elo entre a saúde e a educação" (15).

Tal proposta sustenta-se na compreensão de que: ser cuidada é uma necessidade primordial da criança; é através do cuidado que o ser se torna humano; e que "o cuidado entra na natureza e na constituição do ser humano"(17). A inserção da criança pequena em qualquer instituição torna essa instituição co-responsável por sua socialização, educação e cuidados. Assim, ainda que o equipamento seja educacional, como é o caso das creches e pré-escolas, o instrumental da pedagogia não é suficiente para que se cumpram todas as suas funções.

\section{REFERÊNCIAS}

(1) Merisse A. Origem das instituições de atendimento à criança: o caso das creches. In: Merisse A, Justo JS, Rocha LC, Vasconcelos MS. Lugares da infância: reflexões sobre a história da criança na fábrica, creche e orfanato. São Paulo: Arte Ciência; 1997. p. 25-51

(2) Kuhlmann Jr. M. Instituições pré-escolares assistencialistas no Brasil (1899-1922). Cad Pesq 1991; 78:17-26.
(3) Ministério da Educação e do Desporto. Secretaria de Educação Fundamental. Referencial Curricular Nacional para a Educação Infantil. Brasília; 1998.

(4) Minayo MCS. O desafio do conhecimento: pesquisa qualitativa em saúde. $2^{\mathrm{a}}$ ed. São Paulo: HUCITEC-ABRASCO; 1993.

(5) Kramer S. O papel social da pré-escola. Cad Pesq 1985; 58: 78-81.
Funções da creche segundo suas trabalhadoras: situando o cuidado da criança no contexto educativo 
Maria De La Ó R. Veríssimo Rosa Maria G.S. da Fonseca
(6) Berger PL, Luckmann T. A construção social da realidade. Petrópolis: Vozes; 1985.

(7) Musatti T. Modalidades e problemas do processo de socialização entre crianças na creche. In: Bondioli A, Mantovani S. Manual de educação infantil: de 0 a 3 anos - uma abordagem reflexiva. Trad. de Rosana Severino Di Leone e Alba Olmi. $9^{a}$ ed. Porto Alegre: Artes Médicas; 1998. cap. 11, p. 189-201.

(8) Bondioli A, Mantovani S. Manual de educação infantil: de 0 a 3 anos - uma abordagem reflexiva. Trad de Rosana Severino Di Leone e Alba Olmi. $9^{\text {a }}$ ed. Porto Alegre: Artes Médicas; 1998. Introdução; p. 13-37.

(9) Avancini M. Pesquisa mostra má qualidade de creches. O Estado de São Paulo. 2000 out 30; Caderno A:7

(10) Rosemberg F, Campos MM, Pinto RH. Creches e pré-escolas. São Paulo: Nobel/Conselho Estadual da Condição Feminina; 1985.

(11) Ariès P. História social da criança e da família. $2^{\mathrm{a}}$ ed. Rio de Janeiro: Zahar; 1981

(12) Mello AMA. História da Carochinha: uma experiência para educação de crianças abaixo de 3 anos em creche. [dissertação]. Ribeirão Preto(SP): Faculdade de Filosofia, Letras e Ciências Humanas de Ribeirão Preto/USP; 1999.
(13) Nascimento MEP. Os profissionais da educação infantil e a nova Lei de Diretrizes e Bases da Educação Nacional. In: Faria ALG, Silveira MS, organizadores. Educação infantil pós-LDB: rumos e desafios. $2^{\mathrm{a}}$ ed. Campinas: Autores Associados - FE/ UNICAMP; 2000. Cap. 5, p. 99-112.

(14) Veríssimo MLÓR. O olhar de trabalhadoras de creches sobre o cuidado da criança. [tese]. São Paulo (SP): Escola de Enfermagem da USP; 2001.

(15) Maranhão DG. O cuidado como elo entre a saúde e a educação: um estudo de caso no berçário de uma creche.[dissertação]. São Paulo(SP): UNIFESP; 1998.

(16) Kulhmann Jr M. Educação infantil e currículo. In: Faria ALG, Silveira MS, organizadores. Educação infantil pós-LDB: rumos e desafios. $2^{\text {a }}$ ed. Campinas: Autores Associados FE/UNICAMP; 2000. Cap. 3, p. 51-66.

(17) Boff L. Saber cuidar: ética do humano - compaixão pela terra. Petrópolis: Vozes; 1999. 